\title{
CONSIDERAÇÕES ACERCA DO CAMPO JURÍDICO E DA CULTURA POLÍTICA NA PASSAGEM À MODERNIDADE NO BRASIL
}

\section{CONSIDERATIONS ABOUT THE LEGAL FIELD AND POLITICAL CULTURE IN THE TRANSITION TO MODERNITY IN BRAZIL}

DOI: 10.5533/1984-2503-20102303

\section{Fabiana Cardoso Malha Rodrigues}

\section{RESUMO}

Neste artigo analisamos a conjuntura política no Brasil, na passagem à modernidade, a partir da noção de campo, destacando o que de projeto subsiste em meio a uma atmosfera de não intencionalidade nas obras e idéias defendidas pelos atores sociais que atuaram no campo jurídico no Brasil entre 1890 e 1940. Em especial, destacamos a figura de Clóvis Bevilacqua e sua atuação intelectual e política no processo de modernização do direito de família.

Palavras-chave: campo jurídico, cultura jurídica, direito de família, Clovis Bevilacqua.

\section{RESUMEN}

En este artículo analisamos la coyuntura política en Brasil, en el pasaje a la modernidad, a partir de la noción de campo, destacando lo que de proyecto subsiste en medio a una atmósfera de no intencionalidad en las obras e ideas defendidas por los actores sociales que actuaron en el campo jurídico en Brasil entre 1890 y 1940 . En especial, destacamos la figura de Clóvis Bevilacqua y su actuación intelectual y política en el proceso de modernización del derecho de familia.

Palabras-clave: campo jurídico, cultura jurídica, derecho de familia, Clóvis Bevilacqua. 


\section{ABSTRACT}

This article analyses the political situation in Brazil, in the transition to modernity, from field notion. The intentions which remained in a non-intentionality situation in political actions and ideas supported by social actors, who acted in the legal field in Brazil during the passage to modernity, are highlighted. Specially highlighted is Clovis Bevilacqua, his intellectual and political performance in the process of modernization of civil law regarding family matters.

Key-words: legal field, legal culture, family law, Clovis Bevilacqua.

\section{RÉSUMÉ}

Dans cet article, nous analyserons la conjoncture politique du Brésil lors du passage à la modernité à partir de la notion de champ. Nous mettrons en avant ce qui subsiste d'intention au sein d'une situation de non-intentionnalités dans les actions politiques et les idées défendues par les acteurs sociaux du champ juridique brésilien lors du passage à la modernité, entre 1890 et 1940. Nous nous intéresserons plus particulièrement à Clóvis Bevilacqua et à son rôle intellectuel et politique dans le processus de modernisation du droit de la famille.

Mots-clés : champ juridique, culture juridique, droit de la famille, Clovis Bevilacqua.

Neste artigo buscamos estabelecer uma análise da conjuntura política no Brasil, na passagem à modernidade, a partir da noção de campo, destacando o que de projeto subsiste em meio a uma atmosfera de não intencionalidade nas obras e ideias defendidas pelos atores sociais que atuaram no campo jurídico no Brasil entre 1890 e 1940. Em especial, destacamos a figura de Clóvis Bevilacqua para esta análise. Este artigo faz parte de pesquisa que objetivou discutir as ideias presentes, na passagem à modernidade no campo jurídico brasileiro, sobre as políticas de filiação e casamento nas disputas em torno da aprovação do projeto de Código Civil, confrontando os debates em torno dele, muito tencionados pelo discurso religioso.

Neste artigo, destacamos também as noções de habitus e capital simbólico como elementos pertencentes a esse mesmo universo. São conceitos carregados de potência heurística para nossas análises, que buscam, nas relações sociais e na formação intelectual de um campo específico, questões acerca dos projetos sobre poder e instituições na modernização do Brasil. 
É de fundamental importância para a compreensão e o estabelecimento da ideia de campo a noção de habitus, intimamente ligada à de modus operandi, como elemento que orienta e organiza, na prática, a atividade científica. Aqui estamos nos baseando nas análises de Pierre Bourdieu acerca desses elementos e das suas funcionalidades analíticas. Assim, apontamos para a possibilidade de pensar a conjuntura política no Brasil da virada do século XIX para o século XX como campo político, especificamente, e de pensar os intelectuais do período por nós destacados como possuidores de um modus operandi ou habitus.

Tomando, na definição de Pierre Bourdieu, o habitus como "um conhecimento adquirido e também um haver, um capital (de um sujeito transcendental na tradição idealista)" ${ }^{\text {, }}$, chamamos a atenção para as similitudes presentes não só na formação intelectual, como também em toda a trajetória individual desses atores sociais que atuaram nesse panorama político do período estudado. Assim, trabalhamos com a ideia de um habitus presente nesse campo de forma muito específica, que nos possibilitará a ampliação de nossas análises, partindo das formações intelectuais desses atores, passando por suas trajetórias individuais e apontado para os projetos políticos presentes no período estudado.

Pierre Bourdieu ainda apontou para o habitus como gerador de uma estratégia prática que dá sentido ao jogo, extinguindo a necessidade de raciocinar para se orientar e se situar num espaço. Dessa forma, saiu da filosofia da consciência, mas não esvaziou a sua capacidade prática de construção de objetos.

Trazendo essa questão para a nossa análise, apontamos para uma espécie de "estratégia prática" existente no campo político enquanto considerações exteriores aos atores sociais, muitas vezes condicionadas por ideologias do período, ou elementos que subsistem independentemente da vontade de qualquer um; muitas vezes também produtos de outros campos, mas que não representam alijamentos nas escolhas filosóficas ou mesmo ideológicas desses atores, apenas mais um complexificador.

Exemplificando essa questão, apontamos para o liberalismo como um desses elementos, que estaria presente no campo político na passagem à modernidade como elemento dessa "estratégia prática", que representaria um ponto diante do qual obrigatoriamente esses atores estarão se posicionando. Ainda outro elemento do campo político na passagem à modernidade é a própria ideia de modernidade, opondo-

${ }^{1}$ BOURDIEU, Pierre (1998). O poder simbólico. Tradução Fernando Tomaz. 2 ed, Rio de Janeiro: Bertrand Brasil, p. 61. 
se, no plano filosófico, à Igreja Católica, assumidamente tomista do final do século XIX, como detentora de uma visão de mundo específica.

Dessa forma, queremos pensar a oposição ao conservadorismo clerical, representado pelo neo-tomismo do século XIX, a partir da assunção de uma tendência liberal que propõe rupturas com esse pensamento, agregando, para isso, alguns elementos de outros campos, como o biologicismo, o positivismo e o evolucionismo. Esse movimento de disputa entre uma tendência liberal e o neo-tomismo estará sendo pensada como um elemento agregador dessa geração de meados do século $\mathrm{XIX}$, ou seja, como um ponto diante do qual haverá a necessidade de definição de posições teórico-políticas.

Também concordando com Pierre Bourdieu, entendemos que, dessa forma, o campo específico estudado, possuidor de um habitus, não pode ser pensado como um universo autônomo de relações sociais; ao contrário, ele sempre é possuidor de um modo de pensamento relacional. Nesse sentido, o modo de pensamento relacional tende a ser aqui valorizado, na medida em que buscamos em um conjunto de atores sociais pertencentes a um campo específico seus posicionamentos teóricos. Por outro lado, não entendemos esse pensamento relacional como autônomo; ao contrário, entedêmo-lo não só pela questão diante da qual ele é elaborado, mas também pela própria relação que esses atores estabelecem dentro do campo.

Nesse aspecto, salientamos a importância de pensarmos diante do campo político em termos também geracionais, não só pelas relações muitas vezes de compadrio ou familiares que uma geração guardava com a outra, mas também pelas linhas ou correntes de pensamento que se formaram nesse campo e ganharam força na medida em que a geração anterior servia para legitimar um posicionamento.

Também chamamos a atenção para outros elementos compreendidos nesse modo de análise a partir do estabelecimento de campos. Trata-se, por exemplo, do entendimento desse patamar de análise a partir não só do conceito de habitus, que, em princípio, serve para identificá-lo (evidentemente desdobrado também na sua compreensão como "estratégia prática", estando por isso mais afastada do nível da consciência), mas também a partir de relações baseadas em capital simbólico e também em investimentos simbólicos.

Dessa forma, o campo político e seus atores seriam passíveis de delimitação a partir do estabelecimento desse habitus aliado ao capital simbólico e ao investimento simbólico nele presente. Em nossa análise do campo político, buscamos nesses atores 
a compreensão do habitus específico do campo, bem como a análise do capital simbólico e do investimento simbólico por eles realizado, à medida que se inseriam nesse campo.

Para uma melhor compreensão deste outro conceito, o de geração, buscamos na obra de Sergio Miceli alguns elementos que nos forneçam maior clareza. Especificamente, estamos nos referindo ao seu livro Intelectuais à brasileira ${ }^{2}$, no qual está reunido o conjunto de seus trabalhos sobre intelectuais brasileiros. Em especial, destacamos a sua primeira análise: Poder, sexo e letras na república velha (estudo cínico dos anatolianos).

Nosso objetivo é melhor construir uma análise do quadro intelectual do campo político e jurídico durante o processo de modernização do Brasil. Queremos aqui refletir sobre alguns atores sociais e os lugares nos quais estão colocados dentro desse mesmo campo. Em especial, destacamos neste artigo Clóvis Bevilacqua. Tentaremos ver esse intelectual do campo jurídico inserido na conjuntura histórica e relacionado a outros intelectuais.

Pensamos esse período de modernização (virada do século XIX para o século XX) como representativo também no plano da cultura. Em 1895, fundou-se a Revista Brasileira, da qual, dois anos depois, sairia a Academia Brasileira de Letras. Machado de Assis atingiu, nessa época, a plenitude de sua produção e sua prática literária: em 1891 publicou Quincas Borba; em 1896, as Várias Histórias; e em 1899, Dom Casmurro.

Também em 1895, Farias Brito publicou o primeiro tomo da Finalidade do Mundo, que seria retomado por ele em 1899 e concluído em 1905. Em 1893 e 1896, dois livros vieram marcar a intelectualidade brasileira, projetando nela grandes questões do tempo: A llusão Americana, de Eduardo Prado, e as Cartas de Inglaterra, de Rui Barbosa. Pouco depois, duas outras obras assinalaram o início da reflexão crítica sobre a própria formação cultural brasileira: os Estudos de Literatura, de José Veríssimo, e os Ensaios de Sociologia e Literatura, de Sílvio Romero, ambos editados em 1901.

Destacamos que 1897 é o ano em que Joaquim Nabuco deu início à publicação de Um Estadista do Império. Esse livro seria daí por diante o repositório referente a temas dos historiadores e pensadores políticos. Ele precedeu em três anos Minha

\footnotetext{
${ }^{2}$ MICELI, Sergio (2001). Intelectuais à brasileira, São Paulo: Companhia das Letras.
} 
Formação, a autobiografia modelar, pela qual nos é dado alcançar os ideais, as limitações e os problemas formativos do intelectual da elite daquela época.

Olavo Bilac, de 1888 a 1902 (Poesias), criou sua obra poética, talvez a que mais profundamente influenciou o gosto literário da temporalidade em tela. Em 1898, o poeta Raimundo Correia publicou suas Poesias. Em 1901, o advogado Edmundo Bittencourt fundou o Correio da Manhã. Em 1902, apareceu Canaã, de Graça Aranha. Nesse mesmo ano, surgiu o livro que voltaria a inteligência brasileira para a compreensão do meio físico e marcaria um dos eixos permanentes de nossa vida cultural: Os Sertões, de Euclides da Cunha. ${ }^{3}$

Propomos construir esta análise tendo Tobias Barreto como elemento que faz a transição (no plano ideológico) de uma geração anterior para a posterior, a partir dos campos nos quais estão atuando na virada do século XIX para o século XX (político e jurídico). Desse modo, entendemos que esse período forneceu uma geração de políticos oriundos de uma formação jurídica, polarizada entre uma Escola Paulista e uma Escola Recifence ${ }^{4}$, identificada a partir desse processo externo de modernização da estrutura político-administrativa do Brasil. Essa geração desenvolveu uma linha de análise tendo a questão do nacional como pano de fundo.

Lembramos aqui que a Escola do Recife mostrou-se mais propensa a pensar o nacional já em 1870, segundo Gizlene Neder. No entanto, somente nos anos 1930 é que a Escola de São Paulo refletiria sobre o nacional no que se refere a desenvolver uma análise mais sistematizada. Também apontamos que a Escola de São Paulo seria hegemônica somente na segunda metade do século XX, mais especificamente a partir do Golpe de 1964.

Essa é uma categoria de análise que encontra a sua legitimidade na própria obra escrita por Clóvis Bevilacqua, História da Faculdade de Direito do Recife, que foi reeditada, com o objetivo de comemorar o sesquicentenário da instauração dos cursos jurídicos no Brasil: 1827-1977. Essa obra compreende também a existência de uma certa geração desse período identificada a partir de questões internas, como a sua própria formação e campo de atuação, e também por elementos externos, como a conjuntura política do período.

\footnotetext{
${ }^{3}$ Sobre essa ambiência intelectual e cultural, ver: DANTAS, San Tiago (1949). Dois momentos de Rui Barbosa, Rio de Janeiro: Fundação Casa de Rui Barbosa; do mesmo autor: (1962). Figuras do direito, Rio de Janeiro: Livraria José Olympio Editora.

${ }^{4}$ Sobre considerações acerca das escolas paulista e recifence, ver: NEDER, Gizlene (1995). Discurso jurídico e ordem burguesa no Brasil, Porto Alegre: Sergio Antonio Fabris Editor.
} 
Lembramos que essa geração encontrava na ideia de Independência, de Abolição e de República as grandes questões diante das quais devia se posicionar e, muito ativamente, construía seus discursos, em geral, em apoio a elas, pelo menos nos seus primeiros momentos de introdução nos cursos jurídicos. Esse é um outro elemento que para nós coloca a possibilidade de identificação de uma geração, ou seja, a recorrência das ideias diante das quais deveria se posicionar.

Salientamos que, nesse período, localizamos algumas bases ideológicas nas quais estão assentadas algumas ideias que estariam presentes durante as primeiras décadas da República no Brasil, e também nas posteriores. A nossa referência aqui é direta à concepção de poder e instituições que no Brasil ganhariam forma.

Destacamos alguns elementos práticos utilizados por Sergio Miceli na tarefa de estudo dessa intelectualidade brasileira, como forma de melhor realizar a análise comparativa de seus variados indivíduos. Alguns desses elementos, que por nós também serão utilizados em nossa tarefa sempre que possível, são: destaque para a data e lugar de nascimento, profissão do pai, dilapidação social dos pais (orfandade, falência econômica), estigmas, gestão do capital de relações sociais (destaque para as relações que representam capital social, como por exemplo: padrinho ministro ou pai prefeito da cidade), posição na frataria (primogênito, segundo filho) e carreira dos irmãos, curso superior, carreira e tipo de produção.

Dessa forma, também queremos aqui destacar esses elementos a fim de melhor realizarmos a tarefa de análise comparativa desses atores sociais do campo político brasileiro na passagem à modernidade, ressaltando o caráter de habitus presente juntamente ao capital simbólico e investimento simbólico por eles manejados, a partir de uma concepção de geração.

Assim, trazemos aqui alguns pontos acerca da própria trajetória de Clóvis Bevilacqua. Clóvis Bevilacqua nasceu em Viçosa, na Serra de Ibiapaba, no interior do Ceará, em 4 de outubro de $1859^{5}$, filho do padre José Bevilacqua, Vigário Geral de Viçosa. Interpretamos esse dado, o de ser filho do padre da cidade onde nasceu, como um estigma, ainda tendo como referência teórica o quadro interpretativo de Sergio Miceli, ainda mais se levarmos em conta a não ruptura ideológica de Clóvis Bevilacqua com a Igreja Católica no plano dos sentimentos.

\footnotetext{
${ }^{5}$ Dia da morte de São Francisco de Assis, como nos lembra a autora Gizlene Neder em seu texto: NEDER, Gizlene (2002). Amélia e Clóvis Bevilacqua: o casamento, o casal e a idéia de indivíduo, In ANPUH Regional. Anais...
} 
Clóvis Bevilacqua iniciou sua vida profissional como jornalista em Fortaleza em 1875 e no Rio de Janeiro, em 1876 (segundo Sílvio Meira, há dúvidas sobre o ano, se 1876 ou 1878). Matriculou-se no Externato Jasper e depois no Mosteiro de São Bento, onde foi seu colega o republicano Silva Jardim.

Tendo já fundado um jornal chamado O Livro, ainda no Ceará, fundou também no Rio de Janeiro, juntamente com Pedreira Franco e Paula Ney (colegas do São Bento), o jornal chamado Laborum Literário. Em 1878, ingressou na Faculdade de Direito do Recife, onde foi aluno de Tobias Barreto. Voltou-se, então, para o estudo do direito, fortemente influenciado por seu mestre e pelo empirismo evolucionista alemão, publicando, nessa época, seus primeiros ensaios sobre filosofia e direito comparado. Foi colega na faculdade de Silvio Romero, Phaelante Câmara, Artur Orlando, Graça Aranha, Isidoro Martins Junior, José Higino e João Freitas, sendo este irmão de sua futura esposa Amélia ${ }^{6}$. Clóvis ajudou a fundar outros três jornais: $O$ Escalpelo, $O$ Stereógrafo e Vigílias Literárias, marcados pelo tom panfletário e republicano.

Depois de formar-se em 1882, exerceu diversos cargos públicos, destacando-se na magistratura. Trabalhou como bibliotecário (1884) e como professor catedrático de filosofia (1889) e de legislação comparada (1891) em sua antiga faculdade no Recife. Foi ainda consultor jurídico do Ministério das Relações Exteriores (1906-1934), membro da Corte Permanente de Arbitragem e presidente honorário da Ordem dos Advogados Brasileiros. Como deputado da Assembleia Constituinte do Ceará (1891), colaborou ativamente na elaboração da Constituição Estadual.

Clóvis e Amélia casaram-se em São Luís, no Maranhão, em 5 de maio de 1883, estando ele com 23 anos e ela com 22. Clóvis Bevilacqua era promotor da Comarca de Alcântara, no Maranhão. Seu sogro era o presidente da Província.

Um episódio marcante na vida profissional de Clóvis Bevilacqua, no início de sua carreira, foi o fato de o presidente da Província do Ceará, Antônio Raiol, indeferir seu pleito ao cargo de promotor, em 1883, sob a alegação de que a promotoria não estava vaga, mas ocupada por um leigo.

Clóvis insistiu, invocando o artigo 22 da Lei n. 261, 3-12, de 1841, que dizia que a promotoria só poderia ser ocupada por um leigo caso não houvesse pessoa formada em Direito para tal cargo. Silvio Meira aponta que Clóvis não sabia com quem lidava.

\footnotetext{
6 "Filhos do desembargador Manoel de Freitas, magistrado e presidente das Províncias do Maranhão e Pernambuco. Seu futuro cunhado, Otávio de Freitas foi o fundador da Faculdade de Medicina de Pernambuco. Tratava-se de família muito importante no quadro da administração do Império brasileiro no segundo reinado, cuja origem era o Piauí". Ver NEDER (2002), op. cit., p. 11.
} 
Domingos Antônio Raiol era, na opinião de Meira, homem de grande personalidade e valor moral. De origem paraense ${ }^{7}$, escreveu sobre a cabanagem. Raiol foi presidente de várias províncias: Pará, Alagoas, Ceará e São Paulo.

$\mathrm{Na}$ disputa entre a visão de corte republicano e liberal sobre os direitos e as velhas práticas políticas clientelísticas das oligarquias dirigentes imperiais, Clóvis Bevilacqua terminou derrotado. Raiol afirmava que o leigo que ocupava o cargo de promotor de Aquiraz era uma "pessoa distinta". O argumento mais forte, entretanto, era que, quando vinha a seca, os bacharéis de Recife abandonavam as comarcas, enquanto os leigos lá permaneciam ${ }^{8}$.

Clóvis voltou a Recife, indo residir à Rua Princesa Isabel, no mesmo prédio onde, quando solteiro, mantivera uma escola, passando a viver, novamente, de suas aulas particulares ${ }^{9}$. À época do convite do presidente Epitácio Pessoa para preparar o projeto do Código Civil, Clóvis Bevilacqua já despontava como mestre do Direito, com diversas obras importantes, como Direito das obrigações (1896), Direito de família (1896), Criminologia e direito (1896) e Direito das sucessões (1899).

Clóvis Bevilacqua pertenceu à Academia Brasileira de Letras, como um de seus membros fundadores, ocupando a cadeira número 14, porém não chegou a freqüentála. Sua participação mais importante foi no discurso de recepção a Pedro Lessa (1910). Teve vários atritos com a entidade, sobretudo em 1930, por ter esta recusado a inscrição de sua mulher, a escritora Amélia de Freitas Bevilacqua. Clóvis Bevilacqua morreu no Rio de Janeiro em 26 de julho de 1944.

No texto de Clóvis Bevilacqua História da Faculdade de Direito do Recife ${ }^{10}$, em especial no capítulo intitulado Evolução das idéias. - C) Tobias Barreto e a escola do Recife, Clóvis nos dá, a princípio, alguns dados biográficos de Tobias, apresentados a seguir.

Em 1857, tirou, em concurso, a cadeira de latim da vila de Itabaiana. Em 1861, dirigiu-se à Bahia a fim de seguir a carreira eclesiástica. Desistiu, porém, desse intento, e, na cidade de São Salvador, estudou os preparatórios necessários à matrícula nos cursos superiores. Em fins de 1862, foi para Recife, onde repassou essas disciplinas. Depois de ter permanecido por alguns meses em Sergipe, prestou os seus exames, e,

\footnotetext{
${ }^{7}$ Sílvio Meira, um dos biógrafos de Clóvis Bevilacqua, e grande (senão o maior) historiador do direito civil no Brasil, também é originário do Pará.

${ }^{8}$ Idem, ibidem.

${ }^{9}$ Sobre esses dados ver BRANDÃO, Noemia Paes Barreto (1989). Clovis Bevilacqua na intimidade, Rio de Janeiro: edição da autora.

${ }^{10}$ BEVILACQUA, Clóvis (1977). História da Faculdade de Direito do Recife. 2 ed, Brasília: INL.
} 
em 1864, matriculou-se na Faculdade de Direito de Recife. Durante o curso, disputou as cadeiras de latim (1865), no Curso Anexo, e de filosofia, no Ginásio Pernambucano (1867), mas não obteve nomeação, apesar das boas provas exibidas. O concorrente preferido para a cadeira de latim foi o padre Félix Barreto de Vasconcelos e, em filosofia, o Dr. José Soriano de Sousa.

Formou-se apenas em 1869, por ter perdido o terceiro ano, em 1866, em conseqüência de faltas. Ao receber o grau, já era casado e tinha um filho de poucos meses. Casara-se em 11 de fevereiro de 1868. Em 1871, fixou residência na cidade da Escada, onde permaneceu até 1881.

Em 1882, prestou concurso para a Faculdade de Direito de Recife, onde entrou como professor substituto no dia 14 de agosto desse mesmo ano. Esse concurso teve como contendores Augusto de Freitas, Gomes Parente, Lomelino Drummond e Portela. Faleceu em 26 de julho de 1889, e os seus ossos foram transportados para Aracaju, onde jazem em uma urna de bronze, embaixo da estátua que ali se ergueu em honra ao "pensador insigne".

Clóvis Bevilacqua dividiu a Escola de Recife, basicamente, em três fases. A primeira fase estendeu-se de 1862 a 1863. Ressaltou que nos anos sessenta, em Recife havia dois estímulos: a paixão teatral e o sentimento patriótico. Castro Alves ocupava também esse cenário em Recife nessa época. Clóvis Bevilacqua aponta que ele nasceu na fazenda Cachoeira, junto à cidade de Curralinho (hoje denominada Castro Alves), na Bahia, em 1847. Foi para Recife em 1862, e em 1864 matriculou-se, como Tobias, na Faculdade de Direito de Recife, mas perdeu o ano por faltas. Em fins de 1867, seguiu para a Bahia, e, em 1868, para São Paulo. Em uma caçada, aos 11 de novembro desse ano, feriu-se casualmente no calcanhar, tendo que amputar o pé, no Rio de Janeiro. Regressou à Bahia em 1869, e veio a falecer, em São Salvador, em 6 de julho de 1871.

Segundo Sílvio Romero e Clóvis Bevilacqua, entre a primeira e a segunda fase da Escola de Recife, houve um período de transição, em que o hungoísmo se transformou em realismo, com Celso Magalhães, Generino dos Santos, Sousa Pinto e Inglês de Sousa. A segunda fase da Escola de Recife começou pelos anos de 1868 a 1870 e foi até 1882, quando, com o concurso realizado por Tobias Barreto, iniciou-se a fase jurídica.

Clóvis afirma que Tobias, em 1868, até então espiritualista, começou a inclinarse para o positivismo, e foi a partir dessa orientação que foi elaborado o artigo Moisés 
e Laplace (1870), onde transparece a orientação positivista com relação à famosa lei dos três estados, acentuando-se a passagem do fetichismo para o politeísmo, e deste para o monoteísmo. Em A religião perante a psicologia (1870), há um interessante estudo sobre as idéias de Vacherot, em suas afinidades com as doutrinas de Augusto Comte.

Nessa segunda fase da Escola de Recife, Tobias teve como companheiro Sílvio Romero. Destacamos, nesse ponto, a reação crítica contra o romantismo, desenvolvida a partir de 1870, e sua defesa de tese, em 1875, na qual, pela primeira vez no país, era invocada a autoridade de Rudolf Von Jhering, e na qual o doutorando afirmou o desaparecimento da metafísica, em face da nova concepção do mundo.

Alguns não se afastaram do grêmio de ortodoxia cristã, mas eram vigorosos talentos e, na imprensa, contribuíram para o brilho literário do momento, como Antônio Augusto de Vasconcelos, José Augusto de Sousa Amaranto, Tarquínio de Sousa e Oliveira Santos. Outros, sem tomar parte no combate das ideias filosóficas ou políticas, preferiam ficar ao lado de Polímnia, a musa do lirismo. Entre estes estavam Fernandes Belo, Homem de Siqueira, Ribeiro Gonçalves e Virgílio Brígido.

Clóvis Bevilacqua ainda lembra que, pelos anos de 1874 e 1875, houve, no Ceará, um movimento espiritual que não foi meramente literário, como seria depois o da Padaria espiritual, porém igualmente filosófico e religioso. As conferências realizadas na Escola Popular tiveram essa feição. Foram realizadas essas conferências em 1875, e nelas vemos citados Augusto Comte, Buckle, Taine e Spencer.

A terceira fase da Escola de Recife iniciou-se com o concurso de Tobias, em 1882; foi a fase da nova concepção do Direito. Esse concurso, como Clóvis nos lembra, foi um acontecimento científico de grande importância "pelo valor excepcional de Tobias, que tinha de enfrentar Augusto de Freitas, talento vigoroso e aplicação correspondente, e pela arremetida que desmoronou o velho edifício da metafísica jurídica”. ${ }^{11}$

A dissertação de Tobias versou sobre a Extensão da idéia de mandato, de que trata 0 art. $4^{\circ}$ do Código Criminal. A prova escrita teve por objeto a tese seguinte: Conforma-se com os princípios da ciência social a doutrina dos direitos naturais e originários do homem?. A prova oral foi tão empolgante manifestação de força, que a Congregação, por mostrar quanto a impressionara o saber do candidato, pretendeu,

\footnotetext{
${ }^{11}$ BEVILACQUA, Clóvis (1977). História da Faculdade de Direito do Recife. 2 ed, Brasília: INL .
} 
segundo se afirmou, dar-lhe o primeiro lugar na classificação, deixando o segundo em branco e colocando em terceiro Augusto de Freitas. ${ }^{12}$

Tobias Barreto entrou para o campo do Direito através da crítica e da filosofia. Em filosofia do Direito, ele adotara a escola de Jhering e Hermann Post, que refletiam, no Direito, a teoria genealógica de Darwin e Haeckel. Tanto Jhering quanto Tobias consideravam o Direito como um fenômeno social, criado pela própria sociedade, para assegurar a sua vida e desenvolvimento. Assim considerado, o Direito é uma forma de seleção. Se, em nome do darwinismo, Jhering introduziu no Direito o conceito da luta, Tobias, em nome da filosofia monística, viu nele o processo de adaptação das ações humanas à ordem pública, ao bem-estar da comunhão política, ao desenvolvimento geral da sociedade.

Assim, segundo Tobias, o Direito é uma criação humana que se desenvolve com a civilização, ao contrário do que pensavam os teoristas do Direito natural, que o apresentavam, na sua essência, como uma centelha divina, destinada a nos iluminar nas trevosidades da vida, ou como uma ideia universal e necessária, obtida pela razão, pela inteligência, capaz de compreender o absoluto. Sobre direito criminal, Tobias não se deixou conduzir pela escola penal italiana. Assim, a sua posição ficava entre a escola clássica e a positiva, com Krafft-Ebing, Schaumann, Holzendorf, mas ainda não ao lado de Alimena, Carnevale e Tarde, que viriam depois.

Para Tobias, o crime era uma irregularidade social, que a hereditariedade fazia persistir nos indivíduos. Como o Direito era um processo de adaptação da atividade humana aos fins sociais, o crime era elemento perturbador do Direito, e era indispensável que por meios suasórios ou coercitivos se prevenisse ou reprimisse a ação desse elemento perturbador. Cabia essa função à pena, cujo conceito era antes político do que jurídico.

Interessante também é pensarmos nessa geração, assim entendida, como tendo sido responsável por uma ruptura com o neo-tomismo, o que nem sempre implicou uma ruptura total no âmbito dos sentimentos. Dessa forma, rompeu-se com a ideia de política como missão e caridade, em uma oposição, durante o século XIX, à terceira onda tomista (a primeira ocorrera no século XIII, com Santo Tomás de Aquino, e a segunda, no século XVI).

${ }^{12}$ Ibid., p. 363. 
O próprio paradigma científico do século XIX representava um desacordo com o paradigma neo-tomista. Dessa forma, apontou-se para uma hegemonia naturalista, positivista e biologista. Na Inglaterra, o liberalismo conservador era hegemônico, ou seja, filiado a um pensamento aristocrata monarquista, constitucional e baseado na divisão dos poderes.

A partir daqui, queremos apontar para os projetos acerca do poder e das suas instituições na modernização do Brasil como mecanismos contidos nesse campo político, o qual, por meio dos atores sociais que nele atuaram e a partir das relações nele estabelecidas, definiu algumas questões que ultrapassaram esse período de modernização e constituíram-se em elementos da República brasileira. Em especial, fazemos referência aqui às questões ideológicas da modernização brasileira, ou seja, tomamos a entrada do liberalismo e sua oposição e apropriação como momento fundamental para pensarmos a República no Brasil.

Salientamos que seguimentos comprometidos com correntes conservadoras, no momento da modernização brasileira, serão, muitas vezes, responsáveis por apropriações desse discurso liberal, o que resultará, por um lado, em uma modernização conservadora das instituições e, por outro lado, na permanência de aspectos mais conservadores arraigados no campo político.

Tomar Tobias Barreto como elemento que faz a transição ideológica de uma geração para outra (esta última sendo a geração que vai ocupar os cargos no campo político, no momento da modernização) é possível, pois é ele quem faz a crítica ao modelo de poder colocado, a partir das ideologias mais avançadas do período, realizando, para isso, uma criativa ponte intelectual entre elas. Aqui estamos nos referindo basicamente ao positivismo, ao evolucionismo, ao biologicismo e à resistência à escola italiana de direito criminal.

Daí, tomarmos Clóvis Bevilacqua, seu ex-aluno, como figura do período importante também para a nossa análise - através da qual é possível investigar questões de campo, habitus, capital simbólico e geração - parece-nos natural, já que ele estava entre os que dariam continuidade ao pensamento mais crítico e progressista que guarda relação com o do mestre Tobias Barreto. Aqui vale ressaltar a importância de pensarmos o projeto de Código Civil e não o próprio Código Civil. Acreditamos que o teor do projeto é muito mais identificado com essa crítica ao pensamento conservador e pré-moderno do que o texto aprovado que entrou em vigor em 1916. 
Desse modo, destacamos como o campo político brasileiro da virada do século XIX para o XX estava marcado por uma atuação de grupos com formação no campo jurídico, estando pautado, por um lado, no pensamento mais conservador, que levou adiante acertos com as oligarquias monárquicas, e, por outro lado, no pensamento identificado com correntes liberais, fazendo a crítica justamente ao seu teor mais conservador.

Entendemos que esse campo é palco de um habitus que impõe um intelectualismo para seus membros - exibido tanto no teor das obras que produzem (em vários campos de interesse) quanto no conjunto de referências que fazem, ao desenvolverem suas análises -, aliado a um jogo de relações que, fatalmente, rendeIhes colocação social ligada à máquina político-administrativa. Entendemos também que o capital simbólico desse campo se dá pela própria região de formação desses membros, das suas relações e dos postos que ocupam na máquina administrativa.

Sobre o aspecto de geração, parece que as características que mais nos chamam a atenção são: a recorrência dos lugares de formação superior divididos entre São Paulo e Recife, as coincidentes ideologias do período e os pensamentos teóricos desenvolvidos.

\section{Bibliografia}

ALENCAR, José Almino de; SANTOS, Ana Maria Pessoa dos (orgs.) (1999). Meu caro Rui, meu caro Nabuco, Rio de Janeiro: Fundação Casa de Rui Barbosa.

ALONSO, Ângela (2002). Idéias em movimento. A geração de 1870 na crise do Brasil Império, São Paulo: Paz e Terra.

BARBOSA, Rui (1999). Pensamento e ação de Rui Barbosa. In: Fundação Casa de Rui Barbosa, Brasília: Senado Federal.

BARRETO, Tobias (1977). A Questão do Poder Moderador e Outros Ensaios Brasileiros, Petrópolis: Editora Vozes.

BEVILACQUA, Clóvis (1977). História da Faculdade de Direito do Recife. 2 ed, Brasília: INL.

BOURDIEU, Pierre (1998). O poder simbólico. Tradução Fernando Tomaz. 2 ed, Rio de Janeiro: Bertrand Brasi. 
BRANDÃO, Noemia Paes Barreto (1989). Clovis Bevilacqua na intimidade, Rio de Janeiro: edição da autora.

DANTAS, San Tiago (1949). Dois momentos de Rui Barbosa, Rio de Janeiro: Fundação Casa de Rui Barbosa.

(1962). Figuras do direito, Rio de Janeiro: Livraria José Olympio Editora.

FAORO, Raymundo (1994). Existe um pensamento político brasileiro? São Paulo: Editora Ática S.A.

MICELI, Sergio (2001). Intelectuais à brasileira, São Paulo: Companhia das Letras.

NABUCO, Joaquim (1997). Um estadista do Império. 5 ed, Rio de Janeiro: Topbooks. 2 V.

NEDER, Gizlene (2002). Amélia e Clóvis Bevilacqua: o casamento, o casal e a idéia de indivíduo, In ANPUH Regional. Anais...

(1995). Discurso jurídico e ordem burguesa no Brasil, Porto Alegre: Sergio Antonio Fabris Editor.

ROMERO, Sílvio (1969). Obra Filosófica. Coleção Documentos Brasileiros, Rio de Janeiro: Livraria José Olympio Editora.

SALLES, Ricardo (1996). Nostalgia Imperial: a formação da identidade nacional no Brasil no Segundo Reinado, Rio de Janeiro: Topbooks. 